\title{
Cosmeceuticals: An emerging concept
}

\author{
H. Dureja, D. Kaushik, M. Gupta, V. Kumar, V. Lather
}

Department of Pharmaceutical Sciences, M. D. University, Rohtak, India

Received: 6.8.2004

Revised: 24.11.2004

Accepted: 12.12.2004

Correspondence to:

H. Dureja

E-mail:

harishdureja@rediffmail.com

\begin{abstract}
The use of cosmeceuticals has drastically risen in recent years. This significantly increases the armamentarium of the clinician in improving the treatment of skin, hair, and other conditions. They are at the juncture where wellness meets beauty and growing use by consumers is indicative of their popularity. This article focuses on skin, hair, and other cosmeceuticals and their regulatory aspects.
\end{abstract}

KEY WORDS: Cosmetics; skin; sunscreens, moisturisers.

\section{Introduction}

Today a new hot topic in the cosmetic industry is 'cosmeceuticals', which is the fastest growing segment of the natural personal care industry. Cosmeceuticals (or alternatively, cosmaceuticals) are topical cosmeticpharmaceutical hybrids intended to enhance the beauty through ingredients that provide additional health-related function or benefit. They are applied topically as cosmetics, but contain ingredients that influence the skin's biological function. ${ }^{[1]}$ The Food, Drug, and Cosmetic Act defines cosmetics by their intended use, as 'articles intended to be rubbed, poured, sprinkled, or sprayed on, introduced into, or otherwise applied to the human body for cleansing, beautifying, promoting attractiveness, or altering the appearance.' Among the products included in this definition are skin moisturizers, perfumes, lipsticks, fingernail polishes, eye, and facial makeup preparations, shampoos, permanent waves, hair colors, toothpastes, and deodorants, as well as any material intended for use as a component of a cosmetic product. ${ }^{22}$ These cosmeceuticals, serving as a bridge between personal care products and pharmaceuticals, have been developed specifically for their medicinal and cosmetic benefits. Tracing the origin of cosmetics, the first recorded use of cosmetics is attributed to Egyptians, circa 4000 BC. The ancient Sumerians, Babylonians, and Hebrews also applied cosmetics. In other cases, such as European cosmetic known as Ceruse was used from the second century to the $19^{\text {th }}$ century.

Cosmeceutically active ingredients are constantly being developed by big and small corporations engaged in pharmaceuticals, biotechnology, natural products, and cosmetics, while advances in the field and knowledge of skin biology and pharmacology have facilitated the cosmetic industry's development of novel active compounds more rapidly. Desirable features of cosmeceutical agents are efficacy, safety, formulation stability, novelty, and patent protection, metabolism within skin and inexpensive manufacture. ${ }^{[3]}$ An attempt has been made to review the different types of cosmeceuticals and their regulatory aspects.

\section{Skin cosmeceuticals}

Cosmetics and skin care products are the part of everyday grooming. Protecting and preserving the skin is essential to good health. Our skin, the largest organ in the body, separates, and protects the internal environment from the external one. Environmental elements, air pollution, exposure to solar radiation as well as normal aging process cause cumulative damage to building blocks of skin - DNA, collagen, and cell membranes. Use of cosmetics or beauty products will not cause the skin to change or heal; these products are just meant to cover and beautify. Cosmeceuticals being cosmetic products having medicinal or drug-like benefits are able to affect the biological functioning of skin owing to type of functional ingredients they contain. There are skin-care products that go beyond coloring and adorning the skin. These products improve the functioning/texture of the skin by encouraging collagen growth by combating harmful effects of free radicals, thus maintaining keratin structure in good condition and making the skin healthier. Some of the common cosmeceutical contents are given in Table $1 .^{[4]-[6]}$

OLAY vitamin line, which includes vitamins A, C, D, E, selenium, and lycopene, pycnogenol plus zinc and copper, is a well-known skin care line. ${ }^{[7]}$ The treatment of aging skin with a 
cream containing a hormone such as estrogen results in a fresh appearance with a rejuvenating effect. ${ }^{[8]}$ Kuno and Matsumoto had patented an external agent for the skin comprising an extract prepared from olive plants as a skin-beautifying component, in particular, as an anti-aging component for the skin and/or a whitening component. ${ }^{[9]}$ Dry emollient preparation containing monounsaturated Jojoba esters was used for cosmeceutical purpose. ${ }^{[10]}$ Martin utilized plant extract of genus Chrysanthemum in a cosmetic composition for stimulating skin and/or hair pigmentation. ${ }^{[11]}$ Novel cosmetic creams or gels with active ingredients and water-soluble barrier disruption agents such as vitamin A palmitate have been developed to improve the deteriorated or aged skin. ${ }^{12]}$

\section{Sunscreens}

Regular use of an effective sunscreen is the single most important step to maintain healthy, youthful-looking skin. Mainly, it is the effect of ultraviolet light from the sun that causes most of the visible effects of 'aging' skin. Traditional chemical sunscreens act primarily by binding to skin protein and absorbing ultraviolet B (UVB) photons (280-320 nm) and most are based on para-aminobenzoic acid (or its derivatives), cinnamates, various salicylates and benzophenones, dibenzoylmethanes, anthraline derivatives, octocrylene and homosalate. Avobenzone (Parsol-1789) is a benzophenone with excellent ultraviolet A (UVA) protection. Physical agents, or sun blocks, act as barriers, which reflect or scatter radiation. Direct physical blockers include metal containing compounds such as iron, zinc, titanium, and bismuth. Zinc oxide and titaniumdioxide are highly reflective white powders, but submicron zinc oxide or titaniumdioxide powder particles transmit visible light while retaining their UV blocking properties, thus rendering the sun block invisible on the skin. Some commercially available sunscreens are Benzophenone8, Neo Heliopan MA and BB, Parsol MCX and HS, Escalol 557, 587, and 597. ${ }^{[13]}$ Govier et al. ${ }^{[14]}$ patented sunscreen composition comprising activated platelet factor as an ingredient in a cosmeceutically acceptable carrier. Such a composition in the form of a shaving cream or foam, after shave lotion, moisturizing cream, sun tan lotion, lipstick, etc. assist in restoring the skin to its natural condition when the skin is damaged by cuts, abrasions, sun, wind, and the like.

\section{Moisturizers}

Moisturizers function to smooth out the age lines, help brighten, and tone the delicate skin. Moisturizers usually incorporate emollients to smoothen the skin surface by working their way into the nonliving outer layers of the skin, filling spaces between the layers and lubricating, and humectants to help skin cells absorb and retain moisture in these layers. Healthy Remedies Balancing Lotion has been created for menopausal women containing ingredients, which diminish the appearance of fine lines, and wrinkles, uplift the neck area and moisturize the dry, sagging skin. Some of those ingredients include black cohosh, soy extract, and vitamins A and E. Augmenting the skin's natural moisture balance are a nourishing complex containing hyaluronic acid and a revival complex containing green tea leaf extract, and glutathione. ${ }^{[7]}$ Bleaching agents

Bleaching agents are used for bleaching/fading the various marks and act to block the formation of the skin pigment melanin. Hydroquinone is the most commonly used agent for 'bleaching' brown marks, liver spots, melasma, etc. Kojic acid, extracted from mushrooms, is a slightly less effective agent, either may be compounded with tretinoin or topical steroids, $\alpha$ and $\beta$-hydroxy acids. ${ }^{[13]}$ As with any bleaching agent, aggressive exfoliation, and sun protection are necessary for good results. A synthetic detergent bar was developed containing hydroquinone as a skin-bleaching agent. The bar is maintained at about a pH of between 4 and 7 and includes a compressed mixture of a synthetic anionic detergent, hydroquinone, a stabilizer for hydroquinone, water, a buffer which maintains the $\mathrm{pH}$ of the bar and excipients such as waxes, paraffin, dextrin, and starch. ${ }^{[15]}$ Similarly, a skin bleaching preparation comprising hydroquinone, tertiary butyl hydroquinone, and optionally an additional stabilizer and can additionally contain a buffer to maintain the $\mathrm{pH}$ between about 3.5 and 7.5. ${ }^{[16]}$ Because of the maintenance of low $\mathrm{pH}$ and the presence of a stabilizer, hydroquinone is not oxidized and thus the product is characterized by an extended shelf life.

\section{Hair cosmeceuticals}

The appearance of the hair is a feature of the body over which humans, unlike all other land mammals, has direct control. One can modify the length; color and style of hair according to how one wish to appear. Hair care, color, and style play an important role in people's physical appearance and self-perception. Among the earliest forms of hair cosmetic procedures in ancient Egypt were hair setting by the use of mud and hair coloring with henna. In ancient Greece and Rome, countless ointments and tonics were recommended for the beautification of the hair, as well as remedies for the treatment of scalp diseases. Henry de Mondeville was the first to make a distinction between medicinal therapies intended to treat diseases and cosmetic agents for the purpose of beautification. ${ }^{[17]}$ But today's delineation of cosmetics from pharmaceuticals has become more complex through the development of cosmetics with physiologically active ingredients, i.e. cosmeceuticals. Shampooing is by far the most frequent form of cosmetic hair treatment. While shampoos have primarily been products aimed at cleaning the hair and scalp, current formulations are adapted to the variations associated with hair quality, hair care habit, and specific problems such as treatment of oily hairs, ${ }^{[18]}$ dandruff ${ }^{[19]}$ and for androgenic alopecia ${ }^{[20]}$ related to the superficial condition of the scalp.

Cosmetics for the treatment of hair are applied topically to the scalp and hair. While they can never be used for therapeutic purposes, they must be harmless to the skin and scalp, to the hair, and to the mucous membranes and should not have any toxic effect, general or local, in normal conditions of their use. Mausner ${ }^{[21]}$ has patented a shampoo composition, which cleans the hair and scalp without doing any damage to the fragile biological equilibrium of the scalp and hair. A haircare cosmetic compositions comprising iodopropynyl butylcarbamate and/or a solution of zinc pyrithione in $\mathrm{N}$-acyl ethylenediamine triacetate has been patented, which includes an appropriate carrier and a nonallergenic dry extract of yarrow (Achillea millefolium L.), obtained by oxidation of a wateralcohol solution extract of flower tops of yarrow. The extract 
Table 1

Common cosmeceutical contents ${ }^{[4]-[6]}$

\begin{tabular}{|c|c|c|}
\hline Ingredient & Purported action & Source \\
\hline Vitamins & Antioxidant & Vitamins $\mathrm{A}, \mathrm{C}$, and $\mathrm{E}$ \\
\hline$\alpha$-Hydroxy acids (AHAs) & Exfoliates and improves circulation & $\begin{array}{l}\text { Fruit acids (glycolic acid, lactic acid, citric acid, } \\
\text { tartaric acid, pyruvic acid, maleic acid, etc.) }\end{array}$ \\
\hline$\beta$-Hydroxy acids (BHAs) & Antibacterial & Salicylic acid \\
\hline Essential fatty acids & Smoothens, moisturizes and protects & Linoleic, linolenic, and arachidonic acids \\
\hline Coenzyme Q10 (Ubiquinone) & Cellular antioxidant & Naturally occurring in skin \\
\hline Aloe vera & Softens skin & Aloe vera \\
\hline Arnica & Astringent and soothes & Arnica montana \\
\hline Calendula & $\begin{array}{l}\text { Soothes, softens, and promotes skin- } \\
\text { cell formation }\end{array}$ & Calendula officinalis \\
\hline$\beta$-Bisabolol & $\begin{array}{l}\text { Antiinflammatory, antibacterial, and calms } \\
\text { irritated skin }\end{array}$ & Chamomile flower \\
\hline Ivy & $\begin{array}{l}\text { Stimulates circulation and helps other } \\
\text { ingredients penetrate skin }\end{array}$ & Hedera spp. (ivy family) \\
\hline Panthenol & Builds moisture and soothes irritation & Provitamin $\mathrm{B}_{5}$ \\
\hline Witch hazel & Tones & Hamamelis virginiana \\
\hline Green tea extract & Antioxidant & Green teas \\
\hline Neem oil limonoids & Antimicrobial & Azadirachta indica \\
\hline Pycnogenol & Antiaging effect & Grape seed extract \\
\hline$\alpha$-Lipoic acids, Resveratrol, polydatins & Potent free-radical scavengers and antioxidant & Fruits and vegetables \\
\hline Furfuryladenine & Improves hydration and texture of skin & Plant growth hormone \\
\hline Tetrahydrocurcuminoides & Antioxidant and antiaging & Curcuma longa \\
\hline Centella & $\begin{array}{l}\text { Skin conditioning agent, increases collagen } \\
\text { production, improves texture and integrity of skin, } \\
\text { and reduces appearance of stretch marks }\end{array}$ & Centella asciatica \\
\hline Boswellia & Antiinflammatory and antiaging & Boswellia serrata \\
\hline Coriander seed oil & $\begin{array}{l}\text { Antiinflammatory and antiirritant, skin- } \\
\text { lightening properties }\end{array}$ & Coriandrum sativa \\
\hline Turmeric oil & Antibacterial and antiinflammatory & Curcuma longa \\
\hline Coleus forskoflii oil & Antimicrobial, aromatherapy/perfumer & Coleus forskoflii \\
\hline Arjunolic extract & Antioxidant and antiinflammatory & Terminalia arjuna \\
\hline Ursolic acid & Antiinflammatory, collagen build-up & Rosemarinus officinalis \\
\hline Oleanolic extract & $\begin{array}{l}\text { Antioxidant, antifungal, improves texture, } \\
\text { and integrity of skin }\end{array}$ & Olive leaf \\
\hline Rosemary extract & Antioxidant, antimicrobial, and antiinflammatory & Rosemarinus officinalis \\
\hline Dry extract from yarrow & Treatment of oily hair & Achillea millefolium \\
\hline Licorice extract & $\begin{array}{l}\text { Skin whitening properties, antioxidant, } \\
\text { antimicrobial, and antiinflammatory }\end{array}$ & Glycyrrhiza glabra \\
\hline Horse chestnut extract & $\begin{array}{l}\text { Supports blood circulation, wound healing effect, } \\
\text { and antiinflammatory }\end{array}$ & Aesculus hippocastanum \\
\hline
\end{tabular}


contains less than $0.5 \%$ by weight of polyphenolic derivatives, is used for the treatment of hair, in particular oily hair, based on extract of yarrow. ${ }^{[18]}$ Buck $^{[20]}$ has patented a method for treatment for androgenic alopecia wherein Liquor Carbonic Detergents are topically administered. It is generally accepted that genetic hair loss arises from the activation of an inherited predisposition to circulating androgenic hormones.

A hair cosmeceutical product includes - conditioning agents, special care ingredients, and hair growth stimulants. Conditioning agents are intended to impart softness and gloss, to reduce flyaway and to enhance disentangling facility. A number of ingredients may be used, mostly fatty ingredients, hydrolyzed proteins, quaternized cationic derivatives, cationic polymers, and silicons. ${ }^{[17]}$ Special care ingredients are aimed at modifying specific problems relating to the superficial scalp. These shampoos are formulated around one or more specific ingredients selected for their clinical effectiveness in these conditions. Accordingly, current antidandruff ingredients are virtually all-effective antifungal agents - zinc pyrithione, octopirox, and ketoconazole. ${ }^{[22]}$ Hair growth stimulants cannot be expected to have any impact on hair growth due to shortcontact time and water dilution. A minoxidil-related compound (2,4-diamino-pyrimidine-3-oxide) is a cosmetic agent with claim of acting as a topical hair growth stimulant. ${ }^{[23]}$ Its target of action has been proposed to be the prevention of inflammation and perifollicular fibrosis. ${ }^{[24]}$ Some degree of efficacy of 2,4-diamino-pyrimidine-3-oxide has been claimed in the prevention of seasonal alopecia. ${ }^{[25]}$ Recent approval in the United States of two new products, Propecia and Rogaine Extra Strength (Minoxidil) 5\%, indicated in men to promote scalp hair growth, have added a new dimension to treatment options offered by physicians in treating androgenetic alopecia. $^{[26]}$

\section{Other cosmeceuticals}

The skin beneath the eye lacks subcutaneous fat and has virtually no oil glands. This delicate skin needs protection and plenty of moisture to replenish and repair, which helps to reduce the signs of premature aging. As the skin ages, it becomes thinner, drier, and rougher. Over-exposure to the elements and to environmental pollution aggravates this condition. Many topical skin-soothing products intervene in this process, but products for this area need to be particularly gentle and specially formulated with ingredients that work from the inside out by interacting with the cells under the skin's surface without irritating the eyes. There are numerous cosmeceutical eye creams that nourish the skin with natural emollients and beneficial nutrients. The other functional ingredients include butcher's broom, chamomile, and vitamin E, antioxidants vitamins A, C and E, green tea and tiare flower, Ginkgo biloba and also cucumber, calendula and $\alpha$-bisabolol, an active constituent of chamomile, to calm irritated skin. A key ingredient in the eye lifting moisture cream - that treats puffiness, irritation, and also protects against future skin damage is yeast which helps to plump up the wrinkles. The eye wrinkle cream helps forestall the signs of aging and generally contains wheat germ and corn oil, squalene and carrot extract. Eye firming fluid has aosain, an algae extract from seaweed that helps the skin to maintain elasticity.
Lawlor had developed dental care compositions, which are useful for providing a substantive composition on the surfaces of oral cavity, which can provide prophylactic, therapeutic, and cosmetic benefits. ${ }^{[27]}$

\section{Regulatory aspects}

The claims made about drugs are subject to high scrutiny by the Food and Drug Administration (FDA) review and approval process, but cosmetics are not subject to mandatory FDA review. Much confusion exist regarding the status of 'cosmeceuticals.' Although there is no legal class called cosmeceuticals, this term has found application and recognition to designate the products at the borderline between cosmetics and pharmaceuticals. ${ }^{[28]}$ Cosmeceuticals are not subject to FDA review and the Federal Food, Drug and Cosmetic Act do not recognize the term itself. It is also often difficult for consumers to determine whether 'claims' about the actions or efficacies of cosmeceuticals are in fact valid unless the product has been approved by the FDA or equivalent agency. Some experts are calling for increased regulation of cosmeceuticals that would require only proof of safety, which is not mandatory for cosmetics. Some countries have the classes of products that fall between the two categories of cosmetics and drugs: for example, Japan has 'Quasi-drugs'; Thailand has 'controlled cosmetics' and Hong Kong has 'cosmetic-type drugs.' ${ }^{[17]}$ The regulations of cosmeceuticals have not been harmonized between the USA, European, Asian and other countries.

\section{Conclusion}

The global trend in the cosmetic industry towards developing 'medicinally' active cosmetics, and in the pharmaceutical industry towards 'cosmetically' oriented medicinal products as part of a current 'life-style' ideology. ${ }^{[29]}$ The future promises increasingly sophisticated formulations for cosmetics and skin-care products. Cosmetic companies are finding ways to deliver small-dose ingredients that do not require medical regulations and to introduce steroids and hormones into lip balms, which would result in production of cosmeceuticals that could help to improve body mass, nail, and hair growth. New challenges will also be presented to government regulatory agencies as more chemicals with true biological activity are invented and tested. Claim substantiation and premarketing testing must also evolve to accurately assess efficacy and safety issues with important implications for total body health. The new vehicles and delivery systems combined with established ingredients will alter percutaneous absorption, requiring re-evaluation of substances with an assumed good safety profile. ${ }^{[30]}$ Biotechnology will also compete directly with the pharmaceuticals and cosmetic businesses. The most influential angle over the coming 5 years will be the links between internal health, beauty, and anti-aging. The next big beauty trend will include skingestibles that will promote beauty from the inside out, borrowing of pharmaceutical terms for cosmetic applications, amino peptides to make the skin more elastic, neuro mediators which are chemicals to tell the brain to be happy and the blurring of boundaries between surgery and cosmetics. The trend towards therapeutic cosmetics is sure to result in the need to obtain a better understanding of modern ingredients and assessment techniques. 


\section{References}

1. Grace R. Cosmeceuticals: Functional food for the skin. Natural Foods Merchandiser 2002;XXIII:92-9.

2. FDA / CFSAN. Is it a Cosmetic, a Drug or Both (or is it Soap?). U.S. Food and Drug Administration, Centre for food safety \& applied nutrition, Office of cosmetics and colors fact sheet, 2002.

3. Dooley TP. Is there room for a moderate level of regulatory oversight? In: Hori W, editor. Drug discovery approaches for developing cosmeceuticals: advanced skin care and cosmetic products. Southborough: IBC Library Series; 1997.

4. Balch PA, Balch JF. In: Prescription for nutritional healing. $3^{\text {rd }}$ ed. Vonore: Avery Publishing Group; 2000.

5. Turkington CA, Dover JS. In: The encyclopedia of skin and skin disorders. $2^{\text {nd }}$ ed. Facts on file, 2002.

6. Duber SD. Natural cosmeceuticals: Driving personal care growth today and tomorrow. Neutraceuticals World 2003;6:58-60.

7. Teneralli MJ. Traditional skin care lines: improving looks with dietary supplements. Neutraceuticals World 2004;7:74-80.

8. Tamm J. Cosmetics for treatment of hair and skin. US Patent 4272508. 1981.

9. Kuno N, Matsumoto M. Skin-beautifying agent, anti-aging agent for the skin, whitening agent and external agent for the skin. US Patent 6682763. 2004.

10. Arquette DJG. Dry emollient composition composing mono-unsaturated jojoba esters. US Patent 6432428. 2002

11. Martin R. Use of atleast one extract of the genus chrysanthemum for assisting skin and/or hair pigmentation. US Patent 6726940. 2004.

12. Smith WP. Barrier disruption treatments for structurally deteriorated skin. US Patent 5720963. 1998

13. Holloway VL. Ethnic cosmetic products. Dermatol Clin 2003;21:743-9.

14. Govier WC. Sunscreen composition. US Patent 4900541. 1990.

15. Filomeno VG. Skin bleaching detergent bar. US Patent 4692261. 1987.
16. Filomeno VG. Skin bleaching preprations. US Patent 4792443. 1988.

17. Trüeb RM. The value of hair cosmetics and pharmaceuticals. Dermatology 2001;202:275-82.

18. Grollier JF, Rosenbaum G. A cosmetic composition for the treatment of hair, in particular oily hair, based on extract of yarrow (Achillea millefolium L). US Patent 4948583. 1990.

19. Shin MS. Hair-care cosmetic compositions having dandruff formationsupression effect. US Patent 5886031. 1999.

20. Buck CJ. Method for treatment for androgenic alopecia. US Patent 5609858. 1997.

21. Mausner JJ. Protein shampoo. US Patent 4140759. 1979.

22. Shapiro J, Maddin S. Medicated Shampoos. Clin Dermatol 1996;14:123-8.

23. Mahé YF, Buan B, Bernard BA. A Minoxidil-related compound lacking a C6 substitution still exhibits strong anti-lysyl hydroxylase activity in vitro. Skin Pharmacol 1996;9:177-83.

24. Jaworsky C, Kligman AM, Murphy GF. Characterization of inflammatory infiltrates in male pattern alopecia: implications for pathogenesis. $\mathrm{Br} \mathrm{J}$ Dermatol 1992;127:239-46.

25. Courtois M, Loussouarn G, Hourseau C, Grollier JF. Periodicity in the growth and shedding of hair. Br J Dermatol 1996;134:47-54.

26. Sawaya ME. Novel agents for the treatment of alopecia. Semin Cutan Med Surg 1998;17:276-83.

27. Lawlor TM. Dental care compositions. US Patent 6685921. 2004.

28. Hammes C. Cosmeceuticals: The cosmetic- drug borderline. In: Hori W, editor. Drug discovery approaches for developing cosmeceuticals: advanced skin care and cosmetic products. Southborough: IBC Library Series; 1997.

29. Zesch A. Cosmetics: definition and legal aspects of the term. Huatarzt 1999;50:243-49.

30. Draelos ZD. New developments in cosmetics and skin care products. Adv Dermatol 1997;12:3-17.

\section{Prof. PREM CHAND DANDIYA ENDOWMENT TRUST 2004 and 2005 BIENNIAL AWARDS}

Professor Prem Chand Dandiya Endowment Trust was formed in 1991 by his students and colleagues. The trust has been organizing annual orations regularly by eminent scientists since 1992. As a further step towards achieving the objectives of the trust, the trustees had decided to institute two annual awards for the Best Research paper and / or Review article / Book namely Motan Devi Dandiya Prize in Pharmacy and Chandra Kanta Dandiya Prize in Pharmacology since the year 1996-97.

Prospective entries for Best Publication Awards for Biannual years 2004 and 2005 accompanied by the three reprints/copies of published research/review article or two copies of the Books published during 2004 and 2005 along with the $\mathrm{CV}$ and photograph(s)of the contributor(s) are invited from those not over 55 years in age, up to November 30, 2005 and should reach to Dr. N.K. Gurbani, Jt. Secretary, Prof. P.C. Dandiya Endowment Trust, Department of Pharmaceutical Sciences, Public Health Training Institute, S.M.S. Hospital Campus, JAIPUR 302 004. Joint author publications submitted for this purpose must accompany a disclaimer by other authors in favour of the author(s) claiming the awards.

All such entries received up to closing date will be referred to Expert Committees, which will decide the awards comprising of a Scroll of Recognition together with Rs.10,000/- each. If there is a reasonable closeness in quality of publication(s) between the top ranking publication(s) and the second best publication(s), a Certificate of Merit may be awarded in addition to each prize to the runners up. The decision of the Expert Committee in this matter will be final. 